\title{
Language Attitude of Pakistani Under-Graduate Students towards Non-Native
}

\author{
Speakers \\ * Dr. Uzma Imtiaz, Assistant Professor \\ ** Dr. Aisha Jadoon, Assistant Professor (Corresponding Author) \\ *** Ali Naqi, PhD Scholar
}

\begin{abstract}
English used by native English speakers was being followed as a standard token of usage for nonnative English speakers for a longer time. However, with the spread of knowledge and technology, the English language across the world has provoked a much-heated debate about these norms whether they should be followed by the non-native English speaker or not. The present paper explores the response of Pakistani undergraduate university students about the effectiveness of the non-native English model of communication by using Kachru's monocentric model which refutes the standard model of English language to focus more on conventional norms together with native politico-cultural needs. For this purpose, this study used a close-ended questionnaire that asked the non-native English speakers responses to the audio of three different English speeches Different varieties of spoken English existing across the Pakistani society point towards the strong influence of culture over language. This research concludes that the English language has now got the status of pluricentricity based on micro-level variation, so it is impossible to rely on a single communication model for language users considering their diversity.
\end{abstract}

Keywords: English, Non-native Speakers, Applied Linguistics, Cultures, Pluricentricity

\section{Introduction}

The spread of English across the world has provoked a much-heated debate about the norms that native English speakers should follow when they communicate in English. For several years, in language pedagogy, practicing the norms of native English speakers or Standard English remained essential. However, in the 1970s, a wave of different concepts and models emerged. These models were introduced, as mentioned by Crystal (2003) and Gnutzman (1999) "English as a global language", Jenkin's (2000) model of "English as an international language", again Jenkin (2006) and Kachru's (1985, 1990) model of "world Englishes" and House (1999) and Seidlhofer's (2001) model of "English as a lingua franca". However, this supremacy of the native speaker model gradually got superseded by the non-native speaker model. The major reason behind this shift was to make local people attuned in communication not only with the non-native speakers but also with the native speakers' since the onset of globalization and the rise of social media. Nevertheless, the debate has now been entered into another sphere that the idea of native speaker model 'should be followed' or 'not followed'.

Viewing the model of Braj Kachru (1982, 1985, 1986, 1990, 1996, 2003) that not only earned invaluableness among researchers of Applied Linguistics, but also emphasizes the implication of nonnative approach towards the English language. Along with warm reception, the non-native model of Kachru also faced criticism by different scholars such as Jenkins, Bruthiaux, Park, Lee, and Pung. The major claim of these critics was that Kachru's model that grounds on artificial constructs, is weak and thin enough to bring out various scenarios in the English countries where English is spoken and used as "L1 (native language)", "L2 (Second Language)", or "FL (foreign language)". They support their argument with Saussure's notion that 'all grammars leak' and the models themselves 'leak'. This expresses their failure to reveal the actual position of English worldwide.

* Fatima Jinnah Women University, Rawalpindi

** Department of Humanities, COMSATS University, Islamabad, Pakistan

Email: aisha.jadoon@comsats.edu.pk

*** Foundation University, Islamabad, Pakistan 
Contrary to this criticism, Kachru establishes his assertion about the validity of his model while saying that the pluralism of English has merged many Englishes in one English. On this note, the model due to its versatility, does not imply that the standard model is better or preferable than other varieties of English. Kachru (1985) argues that the "spread of English has resulted in the development of many Englishes and not the shifting of one model to other countries: 'English now has multicultural identities"” (p. 37). The pluralization of English has led to multicultural identities; as Kachru says, and eclectic attitudes of speakers across the globe. This attitudinal diversity and pervasiveness distinguish all non-native speakers from one another owing to the difference of ideology, geography, and social constructs. Jabeen says that attitudes are the product of beliefs, concepts, and opinions. These perceptible features; beliefs and concepts, are revealed by language. Postmodernists also say that it is a language that describes reality. Thus, attitude in language performs an important role in its spread and has also gained significance in research. From the past few years, language learner's attitude, among different professionals such as teachers, educationists, and linguistics has been the center of debate. More specifically, from the last couple of decades, keeping in view the use of language and the attitude of learners, the research in this area has got remarkable significance (Saidat, 2010). A great amount of research has been and is being conducted to know about the attitude towards language with different language and cultural contexts.

To keep with the English language backdrop in Pakistan, there has been historic tension between English and Urdu despite the fact it is an official language of our country. To put in other words, the attitude of Pakistani speakers towards the English language unconditionally remained ambivalent. Kachru divides the countries; where the English language is spoken, into three circles. The first circle is known "inner circle" with English as the mother tongue or "native language", the second circle is termed as "outer circle" where the English language spread through colonization and the third circle is "expanding circle" where English became the language of communication utilizing trade. In the wake of globalization and glocalization, Manan \& David (2004) claim that trade among countries spread out of the frontier constraints. English language has now become a matter of subsistence and is actively used in almost all the important power spheres. In the case of Pakistan, seventy years have passed of the foreign ruling, the English language is still extensively and widely used in different key public offices such as law and justice, trade, economic and revenue department, executive and legislation, etc. (Ansari, Mehmood \& Mangool, 2015; Rahman, 2003). Pakistani people consider English as a symbol of class and gentility that is believed to be spoken by influential masses of the country. Also, a significant role is ascertained and played by the institutions that impart English language education.

Since the English language gained a significant position in Pakistan, the debate of native and non-native model has also become a necessary subject. Before explaining the "native and non-native model" of English, it is important to detail the criteria of the native model. Does it refer to a person who is born in England or America or Australia? Or does it refer to a person who speaks like English people? These questions, in line with the capacity of the native speaker, develop an intangible and complex concept. Most of the individuals take this phenomenon at face value without further questioning. In addition to this, the English language competence of native speakers is never suspected. Cognitive linguists view the native speaker as the authority over the internalized knowledge of the English grammar.

In Pakistan, researchers have conducted a good amount of research in the area of language attitude. This research shows the attitude of the speakers towards Urdu and different mother tongues such as Pashto, Punjabi, shina, etc. This present study investigates the attitude of the undergraduate students of a public sector university towards native and non-native English speeches. These students are chosen from among them who belong to different parts of Pakistan and speak different languages.

\section{Literature Review}

The historical overview of English language discloses the fact that the term "native speaker" was initially defined by Leonard Bloomfield as "the first language a human being learns to speak is his native language; he is a native speaker of this language" (p. 43). Extending his idea, Davies (2003) argues that his definition encompasses the scope of both "mother tongue and first language", i.e. "the language which was learned first, the language 'tongue' you learned from your mother, biological or not" (p.17). Thus for an individual with restricted language understanding knowledge, an Internet search for the terms 'native speaker' and 'mother tongue' gets confounded with ambiguity since 
Wikipedia redirects the inquiry to an article named First Language. In addition to this, Paikedy (1985) says that the native model is the one which is used by the native speaker with good knowledge of grammar:

The concept of a native speaker, as every linguist knows, is often defined as an individual who has an 'insight' into a specific language or enjoys an 'intuitive' sense of what is grammatical and ungrammatical concerning language use; someone whose native instincts qualify them to be a touchstone or arbiter on linguistic matters relating to their language, especially if they are an 'educated native speaker (p. 26).

Similarly, Sir Randolph Quirk, a linguist, grammarian, and educator asserts his opposing argument about the pluricentricity of SE. He gives his model 'liberation linguistics' in which he argues against those linguists who oppose the imposition of a single standard model on the speakers of all varieties of English and dialects. He emphasizes the implication and prescription of Standard English variety in the British educational system. At the next stage, he also asserts that children should acquire Standard English, which is their right, no matter they are native or non-native. However, Kachru while introducing his idea of the monocentricity of SE refutes the assertion of Quirk which also creates controversy.

Contrary to this, Kachru refutes the criteria of Standard English which confines only the "native speaker model". According to him, the "standard model" of the English language is the one that focuses on the particular or respective cultural and political needs as reflected in the language of English speakers in manifold local centers around the globe. Besides, David Crystal also extends the concept of Standard English while asserting that

- "Standard English" (SE) is a variety or a dialect that has no territorial base.

- The defining language features are grammar, lexicon, and orthography. Pronunciation is not part of the SE definition.

- $\quad \mathrm{SE}$ is the variety with the highest social prestige. Adult members of the speech community usually value SE and want their children to be educated in this variety.

- $\quad$ SE is understood, though not necessarily spoken and written, by most, if not all members of the community, and it is used by administrators, in universities, and courts of law.

- $\quad$ Only a minority of the population speak SE as their mother tongue. Most people speak regional dialects

Furthermore, half a year later, Gerry Abbott (1991) joined the dispute in English Today and offered his solution to the problem, which he perceived as one of imminent mutual unintelligibility among English speakers of diverse regional and national dialects. He proposed a variation on Quirk's model, with English native speakers from the Inner Circle functioning as role models. He used the metaphor of a planetary system in which the outer planets, the non-native varieties, are bound by the "gravitational pull" of the "central cluster of mother-tongue standard Englishes" but concludes his response with the self-critical admission that "my nice planetary system looks suspiciously tidy, and may just turn out to be 'pie in the sky' (57). Besides, Peter Trudgil argues on the SE model in his essay 'Standard English' which also carries forward the idea of Einar Haugen that SE consists of determination, codification, and stabilization. To put in other words, SE is not a language, nor an accent nor even a style or register restriction apply. He concludes that SE is a "social dialect which is distinguished from other dialects of the language by its grammatical form".

Looking into the research in the area of language attitude, a great amount of research has been conducted across the globe. The researchers have tried to summarize some of the relevant and recent researches in the field. At first, the relationship between language attitude and language use was investigated by Mbori (2008) in the Rawandian post-colonial context. His study revealed that there are competing languages in each single useable language domain of Rwanda. In this regard, the users' attitude and their preference of one particular language over the other performs a significant role in the prominence of language. Further, the role of users also determines that how do they relate the features of one language and learning interest with the other. In the same way, Khan (2011) has also researched Pakistani immigrants in Manchester concluded that the people of this community, as they were living in the same culture and social conditions, had favorable chances to the resources of their home languages, even then the competence varies. The findings showed that for communication and interaction English was the dominant and preferred language. 
In addition to this, Goldsmith (2012) has also researched high school students in Galicia to assess the implicit language attitudes of the learners. The findings of this study show that the respondents held different attitudes towards "standard" and "non-standard Galician". Those who speak the "non-standard" Galician variety were not encouraged. Besides, certain stigmas were also attached to the speakers of non- standard variety. Similarly, "Spanish language" speaking in the Galician accent was also not approved by the respondents.

Besides, the research of Kircher (2014), which was conducted to know the attitude of the learners, reveals that there is an overall positive attitude towards English more than towards French. In terms of solidarity and nationalistic attachment, they expressed their deep sense of the French language in private while their eager attitude towards English was more positive than towards French. The phenomenon of "social identity" of the respondents is the major reason for this development. In the same year, Mazrui (2014) examined and identified the signs of language shift emerging in Tanzania and Zanzibar. The research: by using questionnaires and surveys, which was conducted for the doctoral thesis concluded that English is replacing Swahili in the domains of education and its state department (ministry of education). Further, the majority of the population shows keen favor for English as a medium of instruction.

Moving to the scenario of Pakistan, the language attitude always remained a very interesting and important research area. Researchers have conducted a mass amount of research on the major languages of Pakistan which are rich in literature more specifically poetry. These major languages are "Pashto", "Siraiki", "Punjabi", "Sindhi" and "Balochi". Along with these major languages, a good amount of research has now also been carrying on other small languages like Shina and Torwali. For example, the study of Khan (2013) shows the language attitude of Pashto speakers and its relationship with language policies. In this research, he concluded that the participants are in a phase where they are abandoning themselves from their mother tongue gradually while learning and using words of foreign language in communication. However, since Pashtun are devoted to their social and cultural norms, they showed a preference for Pashto to maintain their Pashtun identity.

Besides Pashto, the research of Nazir, Aftab, \& Saeed (2013) and Gilani \& Mahmood, (2014) and John (2015) on the Punjabi language shows that the use of Punjabi language, as compared to Pashtu, is on the decline. Punjabi language, despite rich literature, is combating with the long-held notion of language of agriculturalists. In the metropolis age, when people are moving to cities for education and jobs an excessive importance is given to Urdu and English language in their daily communication. Nazir et al. (2013) have also examined the same linguistic scenario and social conditions which are continuously posing threat to the sustainability of Punjabi on a broader scale. The research of Gilani and Mahmood (2014) also shows that the said language is in the risk zone. They also concluded that Punjabi is a tolerated language as it is neither promoted nor proscribed. Besides, John's (2015) doctoral thesis also shows the ambivalent language attitude towards Punjabi.

\section{Introduction of the Speakers}

\section{Speaker 1: Sheikh Rasheed Ahmad}

Sheikh Rasheed Ahmad was born on 6th November 1950 in Rawalpindi. He is a Pakistani politician. Currently, he is a member of the National Assembly and Federal Minister for Railways from 20th August 2018. He is leading his one member party named "Awami Muslim League". Before presiding his party, he has been a member of the National Assembly, in different tenures, from March 1985 to May 2018. Born in the average family of Rawalpindi, he got an education from Gordon College, Rawalpindi, and studied law in Lahore. He has also served as a member of the federal cabinet in various positions, between 1992 and 1997.

\section{Speaker 2: Fawad Chaudhry}

Born in Dina, a small city of Pakistan, Fawad Ahmed Chaudhry hailed to the politics of Pakistan. He belongs to a Jat family. He started his career as a media person, later he became a politician. He first joined the "All Pakistan Muslim League" (APML). He left it and joined Pakistan Peoples Party, again left it and now in Pakistan tehreek-i-Insaaf. He is currently serving as a Federal Minister for Science and Technology from $19^{\text {th }}$ April 2019. Before this, he served as the Federal Minister for Information and Broadcasting from 20 August 2018 to 18 April 2019. In the poll of 2018, he was elected as a member of the "National Assembly of Pakistan". Besides, he is also holding the position of "Secretary Information of Pakistan Tehreek-e-Insaf" and its spokesperson. In past, when being a member of the Pakistan Peoples Party, he also gave his services in both Prime Minister Yousaf Raza Gillani and Raja 
Pervaiz Ashraf's federal cabinet. He also worked as Special Assistant for information and political affairs to the then Prime Minister from April 2012 to March 2013.

\section{Speaker 3: Rehman Malik}

On $12^{\text {th }}$ December 1951, Abdul Rehman Malik, shortly Rehman Malik, was born in Sialkot, Pakistan. $\mathrm{He}$ is quite a learned man and politician. He completed his graduation (BSc) and post-graduation (MSc) in Statistics from Karachi University, Karachi. He first served in one of the Pakistani secret department named the Federal Investigation Agency (FIA). Now retired from FIA and serving as a politician in Pakistan Peoples Party. He has served as the Interior Minister from 25 March 2008 to 16 March 2013. Before coming into the politics of Pakistan, Rehman Malik served in FIA known as the Federal Investigation Agency as a special agent, subsequently came up to the position of Additional Director General of the same agency in 1993. He worked on this position till 1996. His career at FIA remained very successful. While working as Director, he led and coordinated successful counterterrorist operations both within the country and abroad, including the arrest and extradition of Yousaf Ramzi to the United States in 1995. He was then removed from the Directorship, went to the United Kingdom, and began political activity through the PPP platform.

\section{Analysis of the Selected Data}

The present research activity took place at the department of electronics, Quaid-e-Azam University, Islamabad. The students of BS electronics $2^{\text {nd }}$ semester, whose ages ranged from 20 years of age to 22 years, took part in filling the questionnaires after listening to the audio one by one. Both the boys and girls participated in this activity. For each audio 10 students took part to listen and answer the given questions. Each student was given the freedom to either take part in this activity or to leave at any time.

At first, they were informed about the ambiguity of questions. After this, the audio of the first speaker was played without telling them the name of the speaker. They listened to it carefully and then presented their response to find the speech either close to native standard or non-native standard. The answers of respondents are as followed.

\section{Sheikh Rasheed Ahmad}

\begin{tabular}{ccccccc}
\hline Sr. No. & Accent & Vocabulary & Grammar & Confidence & Understanding & Fluency \\
\hline 1 & 2 & 4 & 5 & 5 & 5 & 5 \\
2 & 3 & 2 & 1 & 3 & 4 & 2 \\
3 & 4 & 3 & 4 & 4 & 4 & 3 \\
4 & 2 & 4 & 2 & 3 & 3 & 4 \\
5 & 2 & 3 & 4 & 3 & 4 & 3 \\
6 & 2 & 3 & 5 & 5 & 4 & 3 \\
7 & 1 & 3 & 4 & 2 & 1 & 1 \\
8 & 0 & 2 & 1 & 1 & 3 & 2 \\
9 & 0 & 2 & 2 & 2 & 4 & 3 \\
10 & 3 & 4 & 4 & 2 & 5 & 3 \\
\hline
\end{tabular}

\section{SHEIKH RASHED AHMAD}

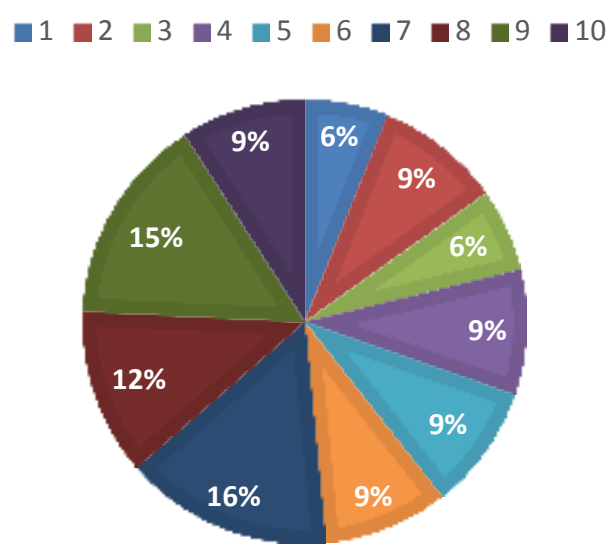


In the case of the first speaker, the response of ten students is different. In the first place, in accent, the option starts from 0 to 5 non-native to native respectively. Seven students found that the accent of the speaker is non-native which was clear from the speech of the speaker. In vocabulary, again seven students answered that the vocabulary which was used by the speaker was easy to understand. In grammar, the options run from 0 to 5 bad to perfect respectively. Six students found that the grammar is good to understand the message. As the speaker is from a Pakistani background, his speech for Pakistani students, in terms of grammar was fine. In confidence, the option runs from 0 to 5 very hesitant to confident respectively. Six students found from the speech that the speaker is confident and delivered his message without any hurdle. In the section of understanding, nine students responded that the speech was understandable. No any confusion could make the students feel confused regarding the understanding of the message. In the last column, the response of seven students was satisfactory. They said that the speaker was fluent.

Keeping in view the aforementioned description which is by non-native speakers towards the English speech of non-native speakers, it can be said that the Quirk model that follows strict rules of grammar and codes is not as appropriate as Kachru, David Crystal and Peter Trudgil model of English are concerned. The model of these scholars provide much convenience to the non-native speakers to communicate in English more effectively. Their models give importance to non-native speakers' intelligibility.

\section{Fawad Chaudhry}

\begin{tabular}{ccccccc}
\hline Sr. No. & Accent & Vocabulary & Grammar & Confidence & Understanding & Fluency \\
\hline 1 & 0 & 2 & 2 & 3 & 5 & 2 \\
2 & 4 & 3 & 2 & 4 & 5 & 4 \\
3 & 2 & 3 & 2 & 2 & 2 & 2 \\
4 & 3 & 4 & 4 & 3 & 4 & 4 \\
5 & 3 & 2 & 3 & 3 & 4 & 4 \\
6 & 2 & 3 & 4 & 4 & 1 & 1 \\
7 & 3 & 4 & 3 & 3 & 2 & 4 \\
8 & 5 & 5 & 5 & 5 & 5 & 5 \\
9 & 2 & 3 & 3 & 4 & 4 & 4 \\
10 & 3 & 2 & 3 & 4 & 5 & 4 \\
\hline
\end{tabular}

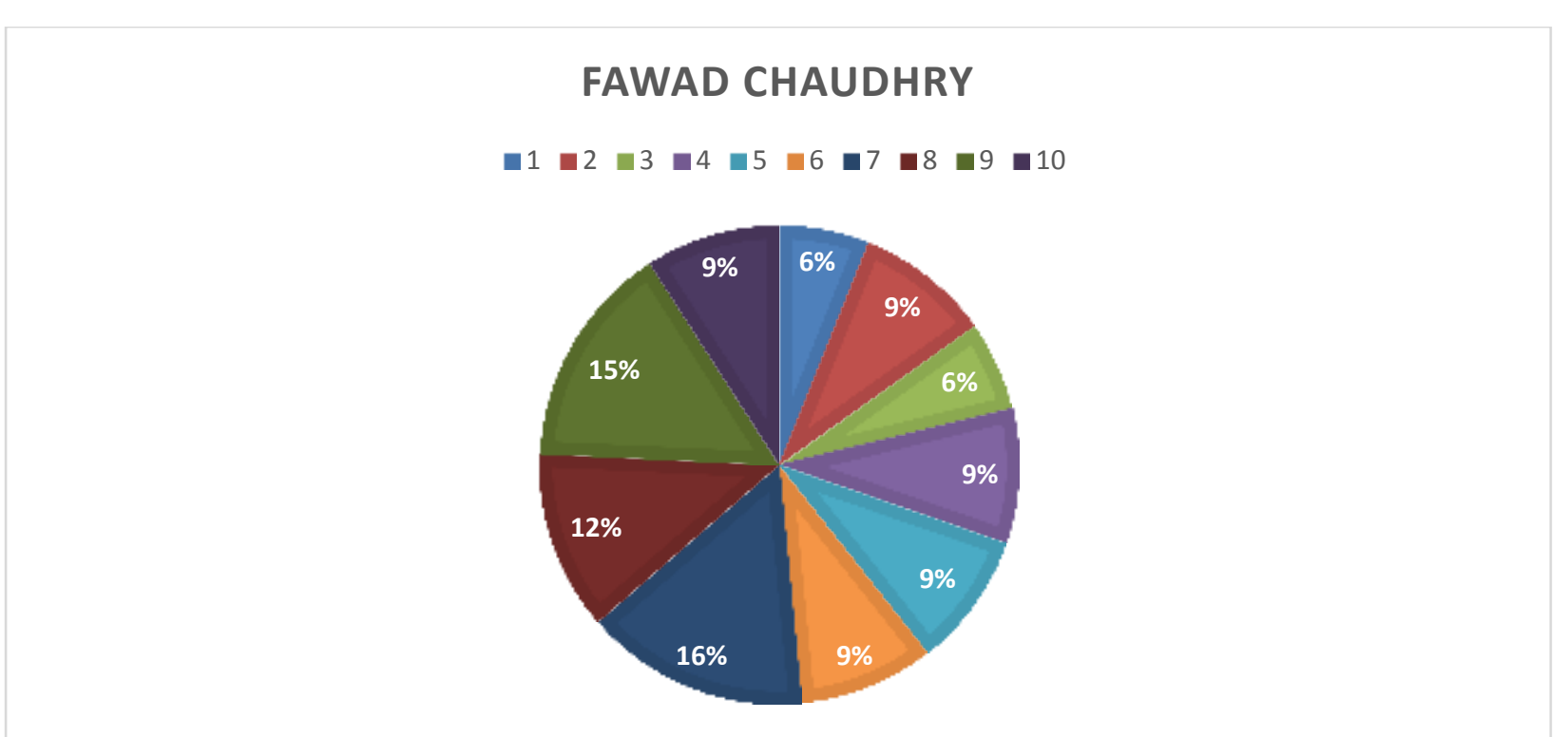

In the case of the second speaker, the response of ten students is different. In the first place, in accent, the option starts from 0 to 5 non-native to native respectively. Four students found that the accent of the speaker is non-native which was clear from the speech of the speaker whereas six students declared the accent of the speaker non-native. In vocabulary, three students answered that the vocabulary which was used by the speaker was easy to understand, four students have mixed opinions neither difficult nor easy whereas the response of three students shows that vocabulary was difficult. 
In grammar, the options run from 0 to 5 bad to perfect respectively. Except for three students, the rest of all seven students found that the grammar is good to understand the message. As the speaker is from a Pakistani background, his speech for Pakistani students, in terms of grammar was fine. In confidence, the option runs from 0 to 5 very hesitant to confident respectively. Nine students found from the speech that the speaker is confident and delivered his message without any hurdle whereas only one student responded that the speaker was hesitant. In the section of understanding, eight students responded that the speech was highly understandable. No any confusion could make the students feel confused regarding the understanding of the message. In the last column, the response of seven students was satisfactory. They said that the speaker was fluent and spoke without any stoppage during his speech.

By considering this description which is again by non-native speakers towards the English speech of a non-native speaker, it can be asserted that Quirk model that follows strict rules of grammar and codes is not influential in the countries where English is not the mother tongue as Kachru, David Crystal and Peter Trudgil model of English are concerned. The model of these scholars provide much convenience to the non-native speakers to communicate in English more effectively. Their models give importance to non-native speakers' intelligibility. According to them, the standard model of the English language is the one that focuses on the respective cultural and political needs as reflected in the language of English speakers in manifold local centers around the globe.

\section{Rehman Malik}

\begin{tabular}{ccccccc}
\hline Sr. No. & Accent & Vocabulary & Grammar & Confidence & Understanding & Fluency \\
\hline 1 & 2 & 3 & 5 & 4 & 5 & 4 \\
2 & 3 & 3 & 2 & 3 & 3 & 2 \\
3 & 2 & 4 & 3 & 4 & 4 & 3 \\
4 & 3 & 3 & 2 & 4 & 4 & 4 \\
5 & 3 & 4 & 5 & 2 & 4 & 3 \\
6 & 3 & 4 & 5 & 5 & 4 & 5 \\
7 & 5 & 4 & 4 & 5 & 5 & 5 \\
8 & 4 & 4 & 5 & 4 & 3 & 5 \\
9 & 5 & 4 & 4 & 4 & 4 & 3 \\
10 & 3 & 4 & 4 & 2 & 5 & 5 \\
\hline
\end{tabular}

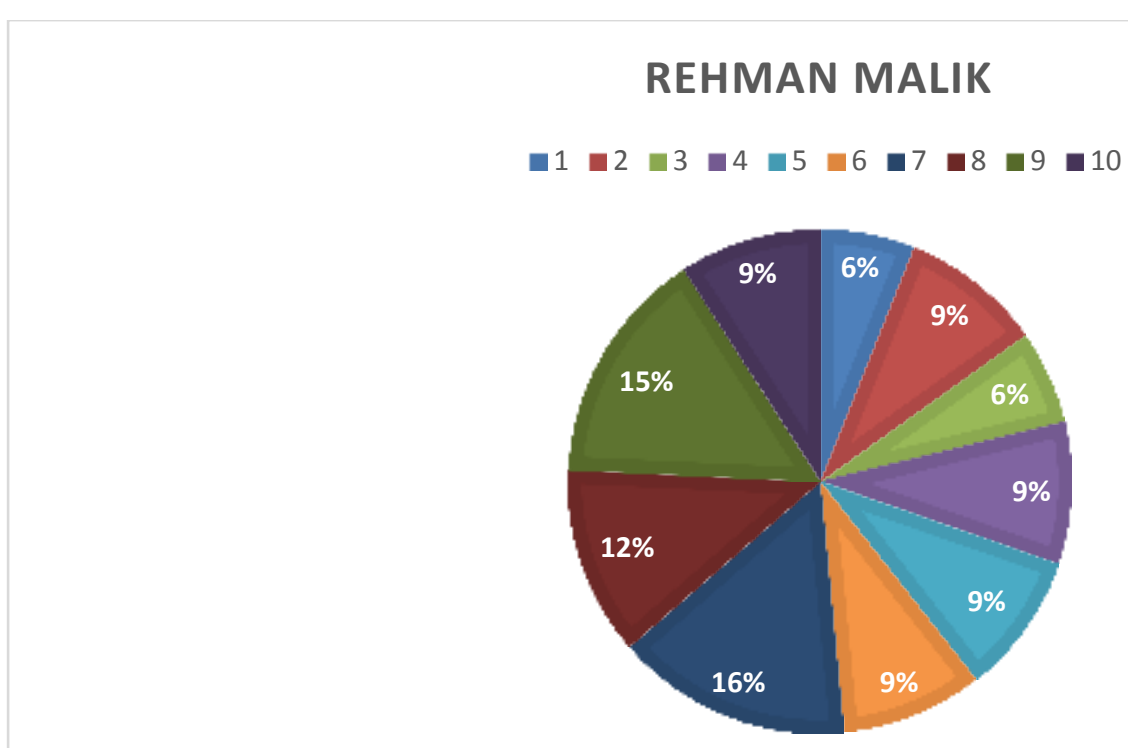

In the case of the third speaker, the response of ten students is different. In the first place, in accent, the option starts from 0 to 5 non-native to native respectively. Two students found that the accent of the speaker is non-native whereas eight students declared the accent of the speaker native. There is a reason, though the speaker got an education from Pakistan, yet he has quite good exposure to foreign countries. He has been living abroad which is obvious from his accent. In vocabulary, all the students answered that the vocabulary which was used by the speaker was rich. Again his 
international exposure is reflected from the use of vocabulary. In grammar, the options run from 0 to 5 bad to perfect respectively. Except for one student, the rest of all nine students found that the grammar is good to understand the message. The speaker is from an educated Pakistani background and also have foreign exposure, his speech for Pakistani students, in terms of grammar was excellent. In confidence, the option runs from 0 to 5 very hesitant to confident respectively. Nine students found from the speech that the speaker is confident and delivered his message without any hurdle whereas only one student responded that the speaker was hesitant. In the section of understanding, all ten students responded that the speech was highly understandable. No any confusion could make the students feel confused regarding the understanding of the message. In the last column, the response of nine students was highly appreciating. They said that the speaker was fluent and very well versed, also spoke without any stoppage during his speech.

So far as the speech of the third speaker is concerned, there is a split point of view about the validity of the Quirk model of English and the other scholars such as Kachru, Crystal, and Trudgil. The case of the third speaker is different, as he has good international exposure. The cultural impact of social impact is obvious from his speech. By considering the major lot of Pakistan which is not familiar with foreign culture nor experienced foreign social construct the model of latter scholars is more appealing than the former one. The model of these scholars provide much convenience to the non-native speakers to communicate in English more effectively. Their models give importance to non-native speakers' intelligibility. According to them, the standard model of the English language is the one that focuses on the respective cultural and political needs as reflected in the language of English speakers in manifold local centers around the globe.

Why did the students show much convenience towards the speech of non-native speakers? As the students, all the students are from far and wide areas of Pakistan, they never had the exposure of foreign countries nor did they attend foreign/English culture school system their understanding of native speakers is not well developed. Again quoting the views of Kachru, Crystal, and Trudgil who put more emphasis on the non-native model implication, it is useful to make a non-native model of English dominant for the educational and interactional purposes.

\section{Conclusion}

The present research has recognized the importance of the native cultural influence on the spoken language of the non-native English speakers. The major purpose of spoken English language, as held by the non-native English speakers, is the communication that is clear and understandable by the listeners and users. Such a view implies the need for an SE model based on intelligibleness and understanding rather than strict criteria of grammar and native-like accent. Since the English language has got the status of pluricentric, it is impossible to demand all the speakers to follow one model of language. Consideration of the micro-level issues is particularly important when addressing the needs of the individual speakers.

In the light of present research, it is concluded with great emphasis that for non-native speakers who speak local varieties of English, instead of the monocentric model, culture-centered models are much more effective and conducive. This research recommends the models of latter scholars for non-native speakers of English due to their effectiveness for the communication in functional terms.

\section{References}

Ansari, S. A., Mehmood, A., \&Mangool, R. A. (2015). Good Governance in Pakistan through Effective Laws: A Case Study of Legislative Drafting and Law Reform Processes in Pakistan. IJLDLR, 3, 11.

Bloomfield, L. 1933, Language, H. Holt and Company, New York.

Bruthiaux, P. Squaring the circles: issues in modeling English worldwide. International Journal of Applied Linguistics. v. 13, n. 2, p.159-178, 2003.

Crystal, D. (2003). English as a Global Language. Cambridge: Cambridge University Press.

Crystal, D., 2003, English as a Global Language, Cambridge University Press, Cambridge.

Davies, Alan, 2003. The Native Speaker: Myth and Reality, Multilingual Matters, Clevedon [etc.].

Gillani, M., \&Mahmood, M. A. (2014). Punjabi: A Tolerated Language Young generations' attitude. Research on Humanities and Social Sciences, 4(5), 129-137.

Gnutzmann, C. (1999). Teaching and learning English as a Global Language.: native and non-native perspectives. Tübingen: Stauffenburg-Verlag. 
Habtoor, H. A. (2013). Language Attitudes of Tigrinya-speaking Parents towards Mother Tongue Maintenance and Their views on Their Children's Shift to Arabic in Riyadh, Saudi Arabia: A Sociolinguistic Investigation. International Journal of English and Education. 2(2) 1-16.

House, J. (1999). Misunderstanding in intercultural communication: Interactions in English as a lingua franca and the myth of mutual intelligibility. In C. Gnutzmann (Ed.). Teaching and Learning English as a Global Language (pp.73-89). Tübingen: Stauffenburg

Jenkins, J. (2000). The Phonology of English as an InternationalLanguage. Oxford: Oxford University Press.

Jenkins, J. (2006). Current perspectives on teaching World Englishes and English as a lingua franca. TESOL Quarterly, 40, 157-181

John, A. (2015).Ideology, language attitude and status of Punjabi in Pakistan. (Unpublished Doctoral Dissertation).Ball State University, Indiana.

Kachru, B. (1985). Standards, codification, and sociolinguistic realism: The English language in the Outer Circle. In R. Quirk \& H. G. Widdowson, English in the World: Teaching and Learning the Language and Literatures (pp.11-30). Cambridge: Cambridge University Press.

Kachru, B. (1990). The alchemy of English. The spread, functions, and models of non-native English. Chicago: University of Illinois Press

KACHRU, B. B. Liberation Linguistics and the Quirk Concern. In: SEIDLHOFER, B. (Ed.) Controversies in Applied Linguistics. Oxford: Oxford University Press, 2003, p. 19-33.

KACHRU, B. B. The Other Tongue. English Across Cultures. Urbana, Ill. University of Illinois Press, 1982.

KACHRU, B. B. Standards, codification, and sociolinguistic realism: The English language in the outer circle. In: Quirk, R. and H. Widdowson, (eds.) English in the World: Teaching and Learning the language and the literature. Cambridge: Cambridge University Press, 1985.

KACHRU, B.B. World English: Agony and Ecstasy. Journal of Aesthetic Education. v. 30, n. 2, p. 135-155, 1996.

Khan, S. (2011). Language use and attitudes of the British Born Pakistani community in Manchester (Unpublished Masters Thesis). The Univesity of Manchester, UK:

Kircher, R. (2014). Thirty years after bill 101: A contemporary perspective on attitudes towards English and French in Montreal. The Canadian journal of applied linguistics, 17(1), 20-50.

LEE, E. and NORTON, B. The English Language, multilingualism, and the politics of location. International Journal of Bilingual Education and Bilingualism.

Manan, S. A., \& David, M. K. (2014).Mapping ecology of literacies in an educational setting: The case of local mother tongues vis-à-vis Urdu and English languages in Pakistan. Language and Education, 28(3), 203-222.

Mazrui, A. W. (2014). The challenges of language planning and language policy in Tanzania: Investigating language attitudes and language shift in Zanzibar (Unpublished Doctoral Dissertation). Indiana University. USA:

Mbori, B. J. O. I. (2009). The interface between language attitudes and language use in a postconflict context: the case of Rwanda (Unpublished Doctoral dissertation).University of South Africa

Nazir, B., Aftab, U., \& Saeed, A. (2013). Language Shift-The Case of Punjabi in the Sargodha Region of Pakistan. Acta Linguistica Asiatica, 3(2), 41-60.

Paikeday, T.M., 1985, the Native Speaker Is Dead! An Informal Discussion of a Linguistic Myth with Noam Chomsky and Other Linguists, Philosophers, Psychologists, and Lexicographers, Paikeday, Toronto.

PARK, J. S-Y, and L. WEE. The Three Circles Redux: A Market-Theoretic Perspective on World English. Applied Linguistics. v.30, n.3, p.389-406, 2009.

Rahman, T. (2006). Language Policy, multilingualism, and language vitality in Pakistan. Trends in linguistics studies and monographs. Islamabad: Summer Institute of Linguistics.

Saidat, A. M. (2010). Language attitude: The case of Jordan. International Journal of Academic Research, 2, 235-243.

Seidlhofer, B. (2001). Closing the conceptual gap: The case for a description of English as a lingua franca. International Journal of Applied Linguistics, 11, 133-158.

Trudgill, P. (1986) Dialects in Contact. Oxford: Basil Blackwell. 